Functional Capacity and Self-esteem of People with Cerebral Palsy 
Abstract

Objective. To assess whether functional capacity predicts self-esteem in people with cerebral palsy.

Method. Cross-sectional observational study of 108 persons with cerebral palsy, aged $16-65$ years, resident in Spain. Self-esteem was captured using the Rosenberg Self-Esteem Scale, and functional capacity using the Barthel Index. Socio-demographic characteristics were recorded. The relationship between the Rosenberg Self-Esteem score and the Barthel Index was analyzed using linear regression.

Results. The Rosenberg Self-Esteem score increased significantly as the Barthel Index increased (regression coefficient $=0.047,95 \%$ CI: 0.017 to $0.078, p=.003$ ). People with a higher level of education, active employment and independent living arrangements tended to have better functional capacity and higher self-esteem.

Conclusion. Greater functional capacity predicted higher self-esteem; this effect is probably partly mediated by education, employment and living arrangements.

MeSH terms. Cerebral palsy, Functional capacity, Self-esteem, Adults, Young people. 
Functional Capacity and Self-esteem of People with Cerebral Palsy

Self-esteem refers to an individual's sense of his or her worth (Blascovich \& Tomaka, 1991). High self-esteem is important for stable personal development (Brooks, 1992) and for life satisfaction (Borg et al., 2008). Adolescents with low self-esteem have poorer mental and physical health, worse economic prospects, and higher levels of criminal behavior during adulthood (McGee \& Williams, 2000; Orth, Robins, \& Roberts, 2008; Trzesniewski et al., 2006). In women, self-esteem has been shown to be correlated with active employment, maintenance of intimate relationships, and health-promoting behavior (Nosek, Hughes, Swedlund, Taylor, \& Swank, 2003). Self-esteem has been reported to be lower in adolescents with cerebral palsy (CP) (Riad, Brostrom, \& Langius-Eklof, 2013), especially girls (Magill \& Hurlbut, 1986), and in women with disabilities (Nosek et al., 2003) than in matched controls. One of the main factors underlying these differences is likely to be functional ability. Alterations in body functions and structure directly affect functional capacity, hindering the performance of activities of daily living, which may in turn cause anxiety and psychological distress, limitations in social participation, personal and working life, and lower self-esteem (Horsman, Suto, Dudgeon, \& Harris, 2010). Nevertheless, few studies have addressed the relationship between functional ability and self-esteem in people with disabilities and most of those that have done so have been restricted to adolescents (Manuel, Balkrishnan, Camacho, Smith, \& Koman, 2003; Riad et al., 2013) and young adults (Gannotti, Minter, Chambers, Smith, \& Tylkowski, 2011; Magill-Evans \& Restall, 1991) with CP or stroke patients (Chang \& Mackenzie, 1998), based on small samples (Magill-Evans \& Restall, 1991; Manuel et al., 2003), were restricted to those able to walk (Riad et al., 2013) or were conducted over ten years ago.

To fill this gap, we performed a study with the objective of assessing whether functional capacity, with respect to activities of daily living, predicted self-esteem in a sample 
of adults and young people with $\mathrm{CP} . \mathrm{CP}$ is composed of a group of movement and posture disorders, caused by a non-progressive insult to the developing brain of the fetus or young infant, which may result in functional limitations (Bax et al., 2005). Sensory, cognitive, perceptive, communication, or behavioral alterations or growth disorders may also be present. The prevalence of CP in Europe is 1.77 per 1000 live births (Sellier et al., 2016) and 46\% of children with CP are unable to walk unaided at age 5 years (Beckung, Hagberg, Uldall, \& Cans, 2008). We chose CP as the disability of interest because its effects are present throughout the life-course, including the critical periods of childhood and adolescence when both functional skills and self-esteem are developing, and because it manifests as a range of impairments whose severity varies from mild to severe.

We hypothesized that people with better functional ability would have higher selfesteem.

\section{Method}

\section{Participants}

The inclusion criteria were: a diagnosis of $\mathrm{CP}$, communication ability (oral, written, or alternative), age $16-65$ years, resident in Spain.

Due to the absence of population-based registers of people with CP in Spain, we used convenience sampling. The principal investigator developed a database of all centers in Spain that she considered she could access, including schools, day care centers, residential homes and occupational centers for people with special needs, and associations for people with physical impairments. She next sent an information sheet about the study to the manager of each center, asking them to bring it to the attention of possible participants, and their family or legal guardian if necessary. She then contacted those who showed an interest in participating, to resolve any queries and provide further information. Those who finally 
agreed to participate were interviewed after they - or their legal guardian - had read and signed a consent form.

\section{Data}

The principal investigator interviewed all participants face-to-face in their school, day center or residential home, between $1^{\text {st }}$ January 2013 and $31^{\text {st }}$ December 2014, to assess selfesteem and functional capacity, and capture the socio-demographic and impairment characteristics summarized in Table 1. Presence or absence of intellectual impairment was obtained from clinical records with the individual's consent, as was information not available from the participant or information about which s/he was unsure. Questions were repeated and explained in more detail if necessary. Those who did not understand the questions after such explanations were excluded. Eight people with anarthria were interviewed using computeraided methods or pictograms.

Outcome variable. We measured self-esteem using the total score of the Rosenberg Self-Esteem Scale (RSES). This instrument has been widely used in studies of self-esteem in the general population (Roth, Decker, Herzberg, \& Brähler, 2008; Sinclair et al., 2010) and among people with disabilities (Blair, 1999; Chang \& Mackenzie, 1998; Manuel et al., 2003; Nosek et al., 2003). It has been translated into Spanish (Martín-Albo, Núñez, Navarro, \& Grijalvo, 2007) and has shown excellent psychometric properties in populations in the US (Sinclair et al., 2010), Germany (Roth et al., 2008) and Spain (Vázquez-Morejón, Jiménez, \& Vázquez-Morejón, 2004); item response theory has confirmed its unidimensionality (Roth et al., 2008). It was developed for use with adolescents (Rosenberg, 1965), but has since been widely used with a variety of groups including adults. It consists of ten items that refer to global feelings of self-worth, five targeted positively and five negatively (see http://personality-testing.info/tests/RSE.php). Each item uses a Likert-type scale with four categories of response ( $1=$ strongly agree, $2=$ agree, $3=$ disagree, and $4=$ strongly disagree $)$ 
or reversely for negatively targeted items. We summed these responses to give a total score which could range from 10 (low self-esteem) to 40 (high self-esteem).

Permission to use this scale was granted by BiblioPRO (http://www.bibliopro.org/).

Putative predictor. We measured functional capacity using the Barthel Index (BI). This instrument has been widely used in rehabilitation research where it has been shown to have excellent reliability and validity (Cohen \& Marino, 2000). It has been used in children and young adults with CP (Ketelaar, Vermeer, \& Helders, 1998; van der Dussen, Nieuwstraten, Roebroeck, \& Stam, 2001), is brief and simple to administer, and has been translated into Spanish (Baztán et al., 1993). It consists of ten items used to assess aspects of functional capacity with respect to activities of daily living: feeding, bathing, grooming, dressing, bowels, bladder, toilet use, transfers (bed to chair and back), mobility (on level surfaces) and stairs. Responses have two, three or four possible categories, each of which is assigned a number of points depending on its perceived importance (Mahoney \& Barthel, 1965). These points are summed to give a total score which can range from 0 (low functional capacity) to 100 (high functional capacity).

Permission to use this scale was granted by the Stroke Center (Mahoney \& Barthel, 1965).

Covariables. The socio-demographic variables listed in Table 1 were recorded. As any relationship between self-esteem and functional capacity might differ between men and women, sex was included as a potential effect modifier. Since age was an extraneous variable likely to be correlated with both the outcome (self-esteem) and the predictor (functional ability), it was regarded as a potential confounder (Rothman \& Greenland, 1998). Education, employment, marital status, and living arrangements were postulated as possible mediating variables which might be on the pathway between functional capacity and self-esteem. Impairment variables describing walking ability, intellectual impairment and neuromotor 
disorder were recorded. Categories of variables comprising less than $10 \%$ of participants were amalgamated with closely related categories.

Assessment of representativeness of sample. Spanish census data report that, among those with $\mathrm{CP}$ in Spain, aged 6 years and over, 52\% are male (Instituto Nacional de Estadística, 2008)., compared with 51\% in our sample (aged 16-65 years). These data did not report the breakdown by age or impairment of people with CP in Spain, but among the general population in Spain aged 16-65 years on 1st January 2014, 15\%, 46\% and 39\% were in age groups 16-25, 26-45 and 46-65 years respectively (Instituto Nacional de Estadística, 2016), compared with $11 \%, 54 \%$ and $35 \%$ respectively in our sample. Among those recorded on 13 population-based registers of people with $\mathrm{CP}$ in Europe, 52\% were able to walk (Surveillance of Cerebral Palsy in Europe (SCPE), 2002), compared with 23\% in our sample.

\section{Statistical analysis}

Descriptive statistics. We first summarized the distribution of RSES, BI scores and the covariables. To compare BI and RSES between groups with different socio-demographic and impairment characteristics we used the non-parametric Mann-Whitney U-test for dichotomous variables and the Kruskal-Wallis test for polytomous variables (Altman, 1990).

Hypothesis testing. To analyze the relationship between RSES and BI, we initially used simple linear regression (Altman, 1990), with RSES as the outcome and BI as the predictor. In order to assess whether the effect differed between sexes, we repeated this for males and females separately. The model with both sexes combined was then adjusted for each covariable in turn. Both RSES and BI were treated as continuous variables. Covariables were treated as categorical variables, the reference group being the largest group in order to yield narrower confidence intervals for estimated effects in non-reference groups; similar categories were amalgamated if they were not significantly different. We checked that the 
final model satisfied the assumptions of linear regression (Altman, 1990). The p-value for significance was $p<.05$.

\section{Ethics}

This study was approved by the Departamento de Fisiatría y Enfermería of the Faculty of Health Sciences of the University of Zaragoza and by the Clinical Research Ethics Committee of Aragón.

\section{Results}

A total of 108 people participated in the study. The mean age of the sample was 41.3 years. The average RSES was 32.0 points (range: 18-40; standard deviation: 5.2); the median BI was 37.5 (range: 0-100), most people having severe functional dependence.

\section{Descriptive statistics.}

Table 1 shows the distribution of socio-demographic and impairment variables. The sample included similar proportions of men (51\%) and women (49\%). Most participants (89\%) were over 25 years of age. About $20 \%$ had completed higher education but most had not progressed beyond primary school. Most were unemployed or pensioners and the most frequent marital status was single. Almost half were living in a care home and only $7 \%$ were living independently. Most participants (81\%) had spastic CP, 77\% were unable to walk without help, and 19\% had intellectual impairment. Both RSES and BI were significantly $(p<.02)$ higher among people with a higher level of education, in active employment, and living independently or with family.

\section{Hypothesis testing.}

Figure 1 shows the relationship between RSES and BI, with the simple linear regression line and its $95 \%$ confidence interval $(\mathrm{CI})$. The regression coefficient was 0.047 (95\% CI: 0.017 to $0.078, p=.003$ ) (see Table 2a), indicating that RSES increased on average 
0.047 points when $B I$ increased one point. $R^{2}$ was 0.081 , reflecting the wide scatter of points seen in Figure 1 and indicating that BI explained only $8 \%$ of the variation in RSES.

Residuals from this model were checked visually and showed no indication of deviations from the assumptions of homoscedasticity, linearity and normality that underlie linear regression or of outlying points which could have had undue influence on the model. The relationship was similar for both sexes (regression coefficient $=0.038,95 \% \mathrm{CI}$ : -0.004 to 0.081 for males, $0.059,95 \% \mathrm{CI}$ : 0.011 to 0.107 for females).

Adjustment for age as a possible confounder made little difference to this relationship (see Table 2b), the regression coefficient for BI remaining virtually unchanged and highly significant, although those aged 46 - 65 years had a significantly lower RSES than others.

We included each potential mediating variable in the regression in turn (see Table $2 b$ ). Education, employment and living arrangements were significant: those with higher education had a higher RSES score than others by an average of 3.8 points, $95 \% \mathrm{CI}$ : 1.44 to 6.13 ; those who lived independently or with family had a higher RSES by 3.6 points, $95 \% \mathrm{CI}: 1.42$ to 5.90; and those who were students or in active employment had a higher RSES by 3.3 points, 95\%CI: 0.9 to 5.8. However, inclusion of employment or living arrangements resulted in the regression coefficient for BI decreasing substantially and becoming non-significant, reflecting the high correlations between these covariables and BI ( $p$ from Mann-Whitney test $<0.002$ ). The models that included education and living arrangements accounted for the most variance in RSES (16\%). After excluding 16-25 year-olds who their education, entered employment or started living independently, these effects were little changed. As education, employment, living arrangements were highly correlated, ( $p$ from chi-square $<0.0001$ ), it was not possible to develop a more complex model that would have allowed us to disentangle their effects.

\section{Discussion}


We found a statistically significant ( $p=.003$ ) relationship between BI and RSES, which increased by an average of 0.047 points for each increase of one point in BI. This implies that, for example, an increase of 40 points in BI was associated with an average increase of $40 * 0.047=1.82$ points in RSES, which is just over one third of a standard deviation (5.2) of RSES in the sample. The statistical model was robust: the relationship was similar in men and women, consistent across the entire range of BI, unconfounded by age and did not rely on any influential points. Further strengths of our study were that all interviews were conducted face-to-face by the same person, who ensured not only consistency but also a complete absence of missing data, despite the collection of a large amount of information describing socio-demographic factors.

Although we found that functional capacity was a statistical predictor of self-esteem, it is difficult to infer that this relationship is causal. In principle, the most convincing evidence for causality is provided by longitudinal studies, but these may not be enlightening in populations such as those we studied where disability is stable over time. Nevertheless, the robustness-of the association-found in our cross-sectional study suggests that functional capacity influences self-esteem.

More education, active employment and living independently or with family were also statistical predictors of-higher self-esteem. However, these socio-demographic factors were so highly correlated with each other and with BI that it was difficult to determine the underlying factor. They may, as postulated, be on a causal pathway between functional capacity and self-esteem, but alternatively they may be a consequence of higher self-esteem (Nosek et al., 2003); indeed, both pathways could be simultaneously operational (Kline, 2010).

We compared our findings with those in the literature. We found only three studies which considered self-esteem in adults with CP (Gannotti et al., 2011; Magill-Evans \& 
Restall, 1991; Riad et al., 2013). Consistent with our findings, Riad et al. (2013) found that, among 44 people with $\mathrm{CP}$ who could walk, deviations of arm and leg movements were inversely correlated with self-esteem, although the effect was not statistically significant. In conflict with our findings, Gannotti et al. (2011) reported that self-concept was not associated with gross motor function or operational independence in 64 people with CP; and MagillEvans and Restall (1991) found no association between education and self-concept in 19 adults with CP. The differences from our findings may be partly because of the small sample sizes and younger participants (average age 26 years) in these studies.

Studies in closely related populations supported our findings. In a study of adolescents with CP, Manuel et al. (2003) found that self-esteem was significantly correlated with the physician-assessed functional ability. In a cross-sectional study of 881 women, about half of whom had disabilities, Nosek et al. (2003) found that self-esteem was significantly associated with both disability and employment. Although, like us, they postulated that disability influenced self-esteem, they assumed that self-esteem influenced employment whereas we assumed the opposite direction of causality.

\section{Limitations and Future Research}

Selection bias may have arisen in two ways. Firstly, due to the lack of populationbased registers of people with CP in Spain, we were unable to select a random sample from all Spanish people with CP. Our sample over-represented older and more severely impaired adults. However, selection bias is more likely to affect estimates of means than of associations, which were the statistic of interest in the current study (Korn \& Graubard, 1999).

Secondly, our study was conducted in Spain, which could compromise its relevance to other countries. However, societal attitudes in Spain appear to be close to the average of a diverse range of countries (Room, Rehm, Trotter, Paglia, \& Ustun, 2001). Furthermore, 
Spain is one of the 171 countries that have ratified the UN Convention on the Rights of Persons with Disabilities (United Nations, 2006), which obliges states to promote mobility, independent living, education, an accessible environment, employment, and social participation for people with disabilities. Although the USA has not ratified this convention, the Americans with Disabilities Act of 1990 (1991) has similar aims. Both frameworks address the situation during childhood, when functional skills and self-esteem are developing. Therefore, the results of our study are likely to be applicable outside Spain, as the countries that subscribe to these legal instruments are likely to have similar facilitators and barriers to disability.

In addition, intellectual or communication difficulties may have resulted in erroneous responses, which could have attenuated the estimate of the relationship between self-esteem and functional capacity. Finally, interviewer bias may have arisen as the sole interviewer had the same pathology as those interviewed. This may have resulted in interviewees responding more openly with more confidence, and possibly exaggerating, especially for positive responses.

Future studies should use random sampling, stratified by age, so that results can be generalized to the wider population of people with $\mathrm{CP}$. Longitudinal studies would allow stronger inferences about causality. A larger sample would allow an analysis using structural equation modelling, a multivariate technique used to estimate and test supposed causal relationships (Kline, 2010).

National population-based registers of people with CP should be created in Spain, to facilitate epidemiological studies of higher quality which would allow a better understanding of the prevalence of $\mathrm{CP}$ and of the situation and needs of those affected.

Future studies should consider additional factors which might influence self-esteem of people with $\mathrm{CP}$, in particular personality traits such as the "Big Five": openness to 
experience, conscientiousness, extraversion, agreeableness, neuroticism (Karwowski, Lebuda, Wisniewska, \& Gralewski, 2013).

\section{Implications for occupational therapy practice}

- It is important that occupational therapy programs help people with impairment to perform activities of daily living as independently as possible. In addition to the intrinsic benefits, our study shows this is likely to lead to higher self-esteem.

- By working with individuals to improve function and advocating for improved accessibility, occupational therapists can facilitate access to higher education, independent living, and active employment.

\section{Conclusions}

Greater functional capacity predicts higher self-esteem in people with CP. It is likely that education, employment and independent living are on the pathway between functional capacity and self-esteem. National policies should facilitate, through the removal of social, physical and attitudinal barriers, the access of people with severe impairment to higher levels of education, homes where they can live independently and an active working life. 


\section{References}

Altman, D. (1990). Practical statistics for medical research. London: Chapman \& Hall.

Americans with Disabilities Act of 1990, Pub. L. no. 101-336, §2, 104 Stat. 328(1991). USA.

Bax, M., Goldstein, M., Rosenbaum, P., Leviton, A., Paneth, N., Dan, B. et al. (2005). Proposed definition and classification of cerebral palsy, April 2005. Developmental Medicine \& Child Neurology, 47, 571-576.

Baztán, J., Pérez del Molino, J., Alarcón, T., San Cristóbal, E., Izquierdo, G., \& Manzarbeitia, J. (1993). Índice de Barthel: Instrumento válido para la valoración funcional de pacientes con enfermedad cerebrovascular. Revista Española de Geriatría y Gerontología, 28, 3240.

Beckung, E., Hagberg, G., Uldall, P., \& Cans, C. (2008). Probability of walking in children with cerebral palsy in Europe. Pediatrics, 121, e187-92.

Blair, C. E. (1999). Effect of self-care ADLs on self-esteem of intact nursing home residents. Issues in Mental Health Nursing, 20, 559-570.

Blascovich, J., \& Tomaka, J. (1991). Measures of self-esteem. Measures of personality and social psychological attitudes (Robinson, John P.; Shaver, Phillip R.; Wrightsman, Lawrence S. ed.) (pp. 115-160). USA: Gulf Professional Publishing.

Borg, C., Fagerström, C., Balducci, C., Burholt, V., Ferring, D., Weber, G. et al. (2008). Life satisfaction in 6 European countries: The relationship to health, self-esteem, and social and financial resources among people (aged 65-89) with reduced functional capacity. Geriatric Nursing, 29, 48-57.

Brooks, R. B. (1992). Self-esteem during the school years. its normal development and hazardous decline. Pediatric Clinics of North America, 39, 537-550. 
Cohen, M. E., \& Marino, R. J. (2000). The tools of disability outcomes research functional status measures. Archives of Physical Medicine \& Rehabilitation, 81, S21-S29.

Chang, A. M., \& Mackenzie, A. E. (1998). State self-esteem following stroke. Stroke, 29, $2325-2328$.

Gannotti, M. E., Minter, C. L., Chambers, H. G., Smith, P. A., \& Tylkowski, C. (2011). Selfconcept of adults with cerebral palsy. Disability \& Rehabilitation, 33, 855-861.

Horsman, M., Suto, M., Dudgeon, B., \& Harris, S. R. (2010). Ageing with cerebral palsy: Psychosocial issues. Age \& Ageing, 39, 294-299.

Instituto Nacional de Estadística. (2016). National results: Resident population by date, sex and age, 1971, from http://www.ine.es/jaxiT3/Tabla.htm?t=10256\&L=1

Instituto Nacional de Estadística. (2008). Survey on disability, independence and dependence situations 2008, from http://www.ine.es/jaxi/Datos.htm?type=pcaxis\&path=/t15/p418/a2008/hogares $/ \mathrm{p} 02 / \mathrm{mod}$ $\underline{\text { ulo1/10/\&file }=03028 . p x}$

Karwowski, M., Lebuda, I., Wisniewska, E., \& Gralewski, J. (2013). Big five personality traits as the predictors of creative self-efficacy and creative personal identity: Does gender matter? The Journal of Creative Behavior, 47, 215-232.

Ketelaar, M., Vermeer, A., \& Helders, P. J. (1998). Functional motor abilities of children with cerebral palsy: A systematic literature review of assessment measures. Clinical Rehabilitation, 12, 369-380.

Kline, R. (2010). Principles and practice of structural equation modeling. New York: Guilford Press.

Korn, E., \& Graubard, B. (1999). Analysis of health surveys. New York: Wiley \& Sons, Inc. 
Magill-Evans, J., \& Restall, G. (1991). Self-esteem of persons with cerebral-palsy - from adolescence to adulthood. American Journal of Occupational Therapy, 45, 819-825.

Magill, J., \& Hurlbut, N. (1986). The self-esteem of adolescents with cerebral palsy. American Journal of Occupational Therapy, 40, 402-407.

Mahoney, F., \& Barthel, D. (1965). Functional evaluation: The Barthel Index. Maryland State Medical Journal, 14, 56-61.

Manuel, J. C., Balkrishnan, R., Camacho, F., Smith, B. P., \& Koman, L. A. (2003). Factors associated with self-esteem in pre-adolescents and adolescents with cerebral palsy. Journal of Adolescent Health, 32, 456-458.

Martín-Albo, J., Núñez, J. L., Navarro, J. G., \& Grijalvo, F. (2007). The Rosenberg Self-Esteem Scale: Translation and validation in university students. The Spanish Journal of Psychology, 10, 458-467.

McGee, R., \& Williams, S. (2000). Does low self-esteem predict health compromising behaviours among adolescents? Journal of Adolescence, 23, 569-582.

Nosek, M. A., Hughes, R. B., Swedlund, N., Taylor, H. B., \& Swank, P. (2003). Self-esteem and women with disabilities. Social Science \& Medicine, 56, 1737-1747.

Orth, U., Robins, R., \& Roberts, B. (2008). Low self-esteem prospectively predicts depression in adolescence and young adulthood. Journal of Personality \& Social Psychology, 95, 695-708.

Riad, J., Brostrom, E., \& Langius-Eklof, A. (2013). Do movement deviations influence selfesteem and sense of coherence in mild unilateral cerebral palsy? Journal of Pediatric Orthopedics, 33, 298-302.

Room, R., Rehm, J., Trotter, R., Paglia, A., \& Ustun, T. (2001). Cross-cultural views on stigma, valuation, parity, and societal values towards disability. In T. Üstün et al. (Ed.), 
Disability and culture: Universalism and diversity (pp. 247-297). Seattle: Hogrefe \& Huber Publishers: Disability and culture: universalism and diversity.

Rosenberg, M. (1965). Society and the adolescent self-image. Princeton, NJ: Princeton University Press.

Roth, M., Decker, O., Herzberg, P. Y., \& Brähler, E. (2008). Dimensionality and norms of the Rosenberg Self-Esteem scale in a German general population sample. European Journal of Psychological Assessment, 24, 190-197.

Rothman, K., \& Greenland, S. (1998). Modern epidemiology. Philadelphia: Lippincott-Raven.

Sellier, E., Platt, M. J., Andersen, G. L., Krägeloh-Mann, I., De La Cruz, J., \& Cans, C. (2016). Decreasing prevalence in cerebral palsy: A multi-site European population-based study, 1980 to 2003. Developmental Medicine \& Child Neurology, 58, 85-92.

Sinclair, S. J., Blais, M. A., Gansler, D. A., Sandberg, E., Bistis, K., \& LoCicero, A. (2010). Psychometric properties of the Rosenberg Self-Esteem Scale: Overall and across demographic groups living within the United States. Evaluation \& the Health Professions, 33, 56-80.

Surveillance of Cerebral Palsy in Europe (SCPE). (2002). Prevalence and characteristics of children with cerebral palsy in Europe. Developmental Medicine \& Child Neurology, 44, 633-640.

Trzesniewski, K. H., Donnellan, M. B., Moffitt, T. E., Robins, R. W., Poulton, R., \& Caspi, A. (2006). Low self-esteem during adolescence predicts poor health, criminal behavior, and limited economic prospects during adulthood. Developmental Psychology, 42, 381390.

United Nations. (2006). Convention on the Rights of Persons with Disabilities. Resolution 60/232. New York. 
van der Dussen, L., Nieuwstraten, W., Roebroeck, M., \& Stam, H. J. (2001). Functional level of young adults with cerebral palsy. Clinical Rehabilitation, 15, 84-91.

Vázquez-Morejón, A., Jiménez, R., \& Vázquez-Morejón, R. (2004). Escala de Autoestima de Rosenberg: Fiabilidad y validez en población clínica española. Apuntes de Psicología, $22,247-255$. 


\section{Figure caption.}

Figure 1. Scatter plot of the total score of the Rosenberg Self-Esteem Scale and the Barthel Index, showing the estimated regression line, and its 95\% confidence interval in shading.

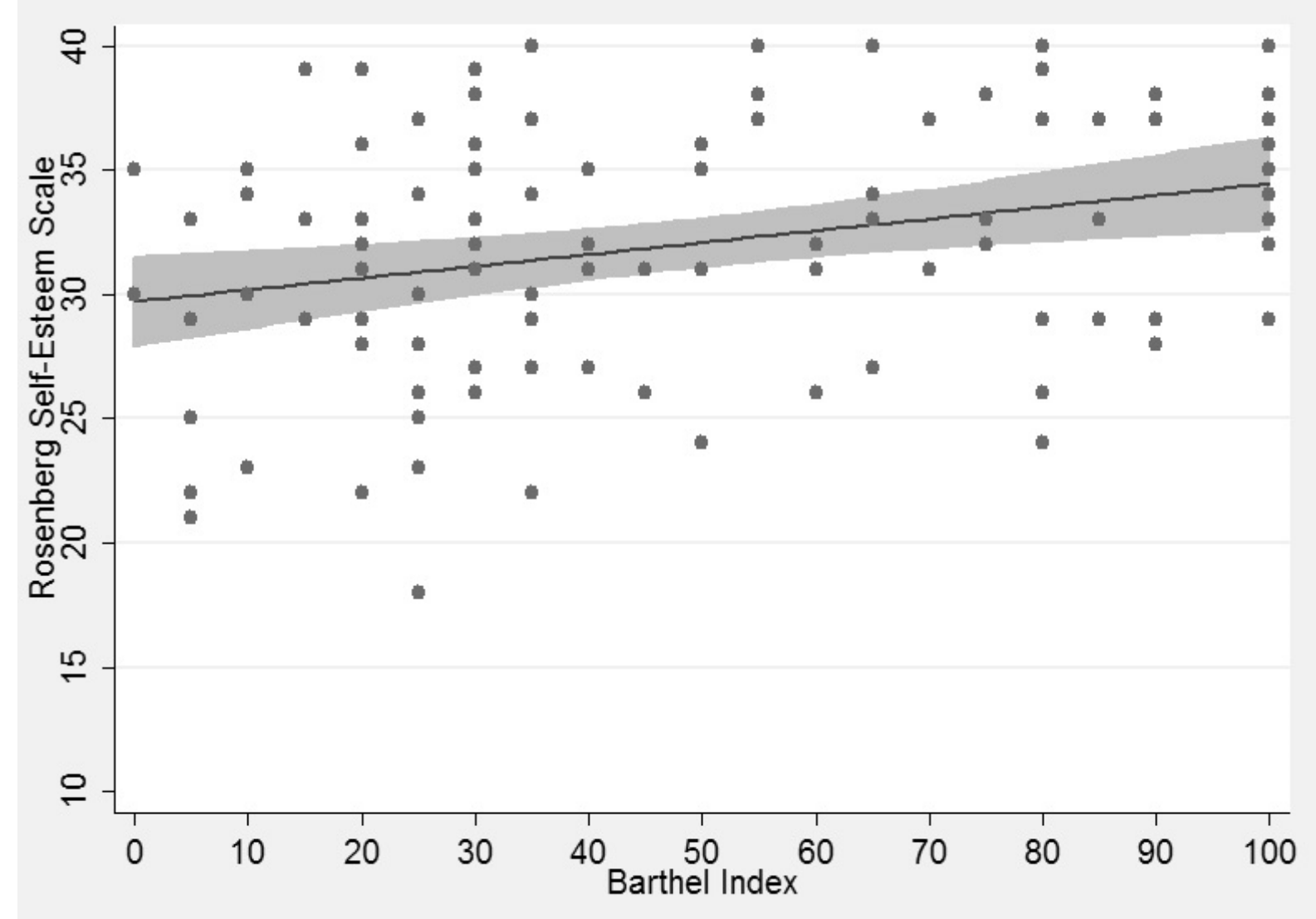




\section{Table 1.}

Distribution of socio-demographic variables, Barthel Index (BI) and the total score of the Rosenberg Self-Esteem Scale (RSES).

\begin{tabular}{|c|c|c|c|c|c|c|}
\hline & \multirow{2}{*}{$\mathbf{n}$} & \multirow{2}{*}{$\%^{a}$} & \multicolumn{2}{|c|}{ Mean (SD) } & \multicolumn{2}{|c|}{$\mathbf{p}^{\mathbf{a}}$} \\
\hline & & & BI & RSES & BI & RSES \\
\hline Total: & 108 & 100 & $48.4(31.1)$ & $32.0(5.2)$ & & \\
\hline
\end{tabular}

Sex:

$\begin{array}{llll}\text { Male } & 55 \quad 51 \quad 51.3(33.3) & 32.3(5.3)\end{array}$

$0.502 \quad 0.564$

$\begin{array}{llll}\text { Female } & 53 \quad 49 & 45.4(28.6) & 31.7(5.1)\end{array}$

\section{Age group:}

$\begin{array}{lllllll}16-25 \text { years } & 12 & 11 & 49.2(33.7) & 32.7(5.8) & & \\ 26-45 \text { years } & 58 & 54 & 50.8(32.9) & 32.9(4.8) & 0.646 & 0.059 \\ 46-65 \text { years } & 38 & 35 & 44.5(27.5) & 30.3(5.3) & & \end{array}$

Highest level of education:

$\begin{array}{lcccccc}\text { None } & 14 & 13 & 33.2(29.1) & 29.1(4.0) & & \\ \text { Primary school } & 43 & 40 & 44.3(29.8) & 31.7(4.8) & & \\ \text { Secondary school } & 16 & 15 & 45.9(30.8) & 31, .3(5.7) & & \\ \text { Post-compulsory } & 12 & 11 & 48.8(27.4) & 30.4(5.8) & & \\ \text { education } & & & & & & \\ & & & & & & \\ \text { Higher education } & 23 & 21 & 66.7(30.7) & 35.6(4.4) & \end{array}$




\section{Employment situation:}

Active employment

or student

$$
23 \quad 21 \quad 69.8(32.5) \quad 35.3(4.7)
$$

Inactive

$<0.001<0.001$

(unemployed or

$85 \quad 79 \quad 42.6(28.2) \quad 31.1(5.0)$

pensioner)

\section{Marital status:}

$\begin{array}{llll}\text { Single } & 92 \quad 85 & 47.2(30.2) \quad 31.8(5.0)\end{array}$

$0.351 \quad 0.363$

$\begin{array}{lllll}\text { With a partner } & 16 & 15 & 55.3(35.7) & 32.9(6.1)\end{array}$

\section{Living arrangements:}

Independently or

with family

$$
30 \quad 28 \quad 69.0(31.9) \quad 35.2(4.7)
$$

Care home

$48 \quad 44 \quad 38.8(28.7) \quad 30.3(5.0)$

$<0.001<0.001$

Day care center

$30 \quad 28 \quad 43.2(24.2) \quad 31.6(4.7)$

(a) The p-value was derived using the Mann-Whitney test for dichotomous variables, and the Kruskal-Wallis test for other variables. Statistically significant $(p<.05)$ values are shown in bold. 
Table 2.

Regression of the total score of the Rosenberg Self-Esteem Scale on the Barthel Index, adjusted for socio-demographic variables.

$\mathbf{B}^{\mathrm{a}} \quad(95 \% \mathrm{CI})^{\mathrm{b}} \quad \mathbf{P}^{\mathrm{c}} \quad \mathbf{R}^{2 \mathrm{~d}}$

(a) Simple linear regression:

\begin{tabular}{lllll}
\hline Barthel Index & 0.047 & $(0.017$ to 0.078$)$ & $\mathbf{0 . 0 0 3}$ & $8 \%$
\end{tabular}

(b) Linear regression, adjusted for each socio-demographic variable:

\begin{tabular}{lllll}
\hline Barthel Index & 0.044 & $(0.014$ to 0.074$)$ & $\mathbf{0 . 0 0 5}$ & $13 \%$
\end{tabular}

Age group

Age $16-45$ years Reference group

Age $46-65$ years $\quad-2.3 \quad(-4.3$ to -0.3$) \quad \mathbf{0 . 0 2 3}$

\begin{tabular}{lllll}
\hline Barthel Index & 0.032 & $(0.001$ to 0.063$)$ & $\mathbf{0 . 0 4 4}$ & $16 \%$
\end{tabular}

\section{Highest level of education}

None, primary or

secondary

Reference group

Higher education

3.8

$(1.4$ to 6.1$)$

0.002

Barthel Index

0.031

$(-0.001$ to 0.064$)$

$0.054 \quad 14 \%$

\section{Employment situation}

Inactive/pensioner

Reference group

Active

3.3

(0.9 to 5.8)

0.007 
employment/student

\begin{tabular}{lllll}
\hline Barthel Index & 0.047 & $(0.016$ to 0.078$)$ & $\mathbf{0 . 0 0 4}$ & $8 \%$
\end{tabular}

Marital status

Single $\quad$ Reference group

With partner $\quad 0.6 \quad(-2.1$ to 3.4$) \quad 0.636$

$\begin{array}{lllll}\text { Barthel Index } & 0.026 & (-0.007 \text { to } 0.058) & 0.122 & 16 \%\end{array}$

\title{
Living arrangements
}

Care home or day

Reference group

center

\author{
Reference group
}

With family or

independently
3.7
(1.4 to 5.9$)$
0.002

(a) B is the regression coefficient.

(b) $95 \% \mathrm{CI}$ is the $95 \%$ confidence interval for $\mathrm{B}$.

(c) $\mathrm{p}$ is the significance of B. Statistically significant $(p<.05)$ values are shown in bold.

(d) $\mathrm{R}^{2}$ is the percentage of variance in the Rosenberg Self-Esteem Scale that is explained by the model. 